\title{
Novel insights on the management of pain: highlights from the 'Science of Relief' meeting
}

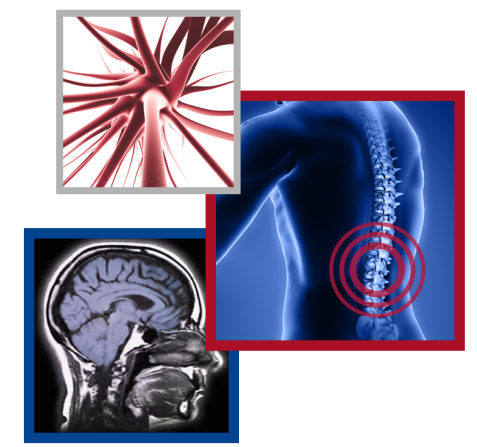

\author{
Praveen Anand ${ }^{1}$, Anthony Dickenson ${ }^{2}$, Gabriele Finco ${ }^{3}$, Franco Marinangeli ${ }^{4}$, Enrico \\ Polati $^{5}$, Patrizia Romualdi ${ }^{6}$, Thomas M Tzschentke ${ }^{7}$ \& Pier Luigi Canonico*,8 \\ ${ }^{1}$ Department of Neurology, Imperial College London, Hammersmith Hospital, London, UK \\ ${ }^{2}$ Division of Biosciences, UCL, London, UK \\ ${ }^{3}$ Dipartimento di Scienze Mediche e Sanità Pubblica, Università degli Studi di Cagliari. UOC Anestesia e Rianimazione, Centro \\ Terapia del Dolore Azienda Ospedaliero-Universitaria di Cagliari \\ ${ }^{4}$ Dipartimento di Medicina clinica, Università degli Studi, Sanità pubblica, Scienza della vita e dell'ambiente dell'Aquila \\ ${ }^{5}$ Anestesia, Rianimazione e Terapia del Dolore, Università di Verona, Verona, Italy \\ ${ }^{6}$ Dipartimento di Farmacia e Biotecnologie, Università di Bologna, Bologna \\ ${ }^{7}$ Grünenthal GmbH, Aachen, Germany \\ ${ }^{8}$ Dipartimento di Scienze del Farmaco, Università del Piemonte Orientale "Amedeo Avogadro", Novara, Italy \\ *Author for correspondence: Pierluigi.canonico@uniupo.it
}

The 'Science of Relief' event, held in Milan on 10-11 May 2019, was aimed at promoting dialog between different stakeholders among scientific associations, pharma industry, healthcare services and related institutions. The goal was to renew interest and attention on the management of pain, sharing new solutions in order to bring the patients and their quality of life to the center of attention. An international group of scientists and clinicians presented and discussed new and known evidence in the field of chronic pain, from physiopathology and diagnosis to the choice of appropriate and timely pharmacological treatments. This paper reports the highlights of those presentations.

First draft submitted: 30 July 2019; Accepted for publication: 12 August 2019; Published online:

2 September 2019

Keywords: capsaicin $\bullet$ central sensitization $\bullet$ lidocaine $\bullet$ management $\bullet$ neuropathic pain $\bullet$ nociceptive pain $\bullet$ pain - peripheral sensitization • tapentadol

Not suffering from pain is a right enshrined in the Italian law number 38/2010 for palliative care and pain therapy; it is a law that embodied a turning point for millions of patients [1]. Although the management of chronic pain in Italy has improved, 9 years after its implementation it is still underestimated and often not adequately assessed or treated. This has major consequences for the quality of life $(\mathrm{QoL})$ of patients, and significant impact on the sustainability of healthcare and social welfare funding. Similar considerations and issues apply to almost all other countries [2-6].

The 'Science of Relief' event, held in Milan (Italy) on 10-11 May 2019, supported by Grunenthal, aimed to promote dialog between different scientific, industry and healthcare stakeholders. The goal was for each stakeholder to contribute insights for improving the management of pain, and share in the vision of new integrated solutions to enhance the QoL of patients.

At this event, an international group of scientists and clinicians presented and discussed new and known evidence in the field of chronic pain, from physiopathology and diagnosis to the choice of pharmacological treatments. This paper reports the highlights of their presentations and conclusions.

\section{Chronic pain: evidence, challenges \& promising new advances}

There have been major advances in the knowledge of basic mechanisms that underlie the onset and the persistence of chronic pain [7]. In particular, pain signaling and modulatory mechanisms change following pathophysiological events, leading to two different major types of pain: neuropathic and nociceptive/inflammatory (Figure 1). Since 


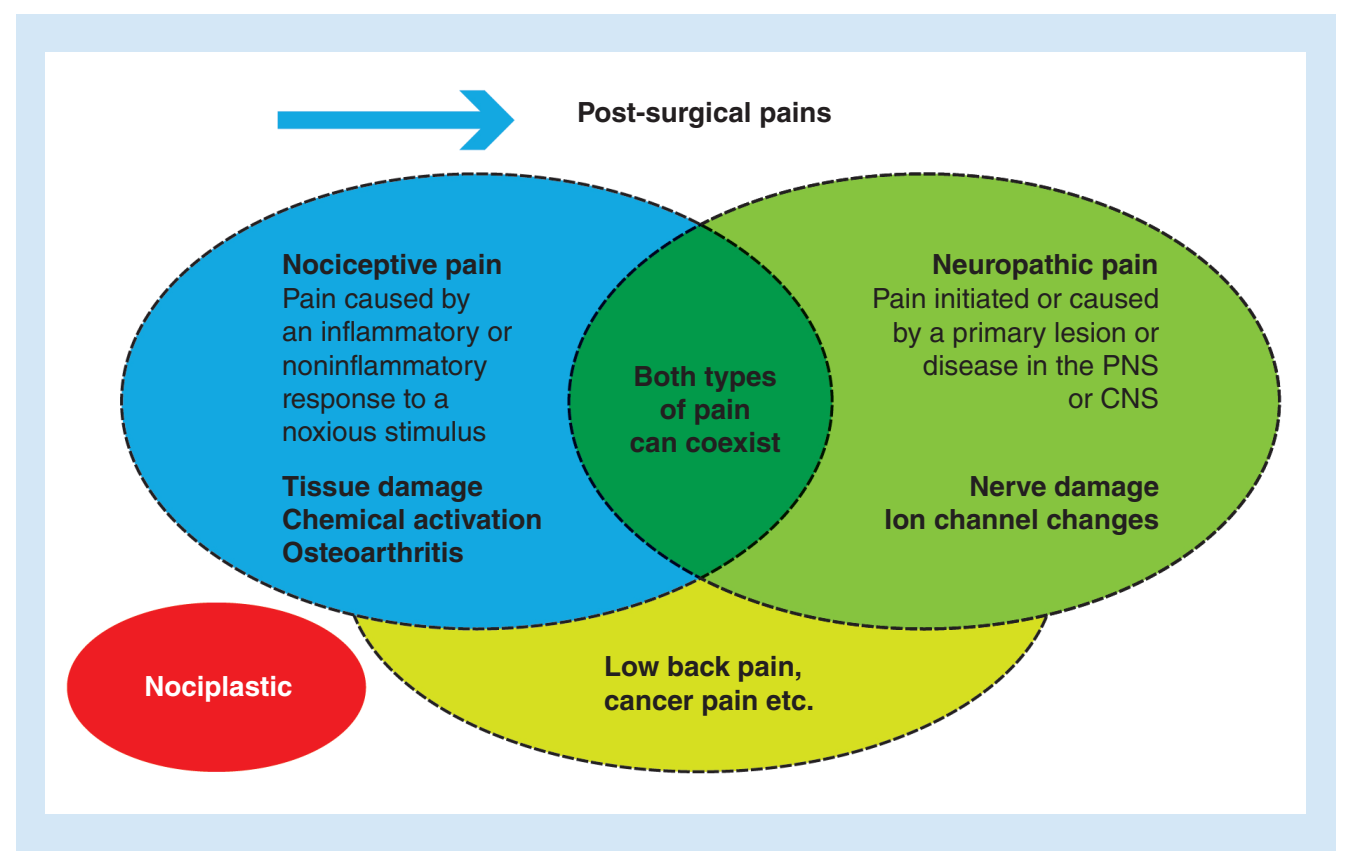

Figure 1. Key types of pain.

CNS: Central nervous system; PNS: Peripheral nervous system.

different chemical ligand and ion channel changes underlie these pain types, their optimal treatments may also differ. However, these pain states do share some common features, for example, loss of inhibition within the CNS.

Peripheral pathophysiology is critical and distinct in the development of chronic pain: tissue and nerve damage elicit the release chemical mediators and changes in ion channels, which in turn induce altered neuronal responses in spinal cord and its projections to the brain. Many CNS structures, interconnected via multiple mechanisms, influence each other $[8]$.

Neuropathic pain has been defined as pain initiated or caused by a primary lesion or disease in the PNS or CNS; this frequently becomes established after prolonged afferent fiber hyperactivity in chronic painful conditions such as diabetic neuropathy. However, neuropathic elements can also be seen in other pain states (e.g., osteoarthritis [OA] or low back pain), which therefore can present as a mixed type of pain, with nociceptive and neuropathic components. Ion channels play a key role in the development and persistence of neuropathic pain, thus providing the rationale for the use of drugs targeting peripheral ion channels; drugs acting on neuroinflammatory process (e.g., NSAIDs) are generally regarded as ineffective in chronic neuropathic pain [7]. There is often a disparity between the pain intensity and the degree of peripheral tissue damage [9]. Wind-up (an amplified response of the second-order neurons), secondary hyperalgesia (a lowering of the pain threshold outside of the area of inflammation), expansion of the peripheral fields of primary sensory neurons, and long-term potentiation (a response of the second-order neurons outlasting the initial painful stimulus) are all phenomena associated with central sensitization [9].

Descending pathways are of utmost importance in the process of adaptation and amplification of pain, since they can modify, especially at the spinal level, the intensity and characteristics of the perceived pain, leading to plastic modifications [10]. More specifically, physiological descending controls produce a final inhibitory effect through the actions of noradrenaline (NA) at spinal $\alpha_{2}$-adrenoceptors, whereas serotonin, by acting on facilitatory spinal $5-\mathrm{HT}_{3}$ receptors, exerts a pronociceptive effect. If the peripheral stimulus persists, high-frequency transmission in nociceptors results in spinal release of neuromodulatory peptides and glutamate. This leads to neural modifications, which in turn determine the onset of central sensitization and promote the progression to chronic pain. In the case of OA and other chronic pain conditions, reduced NA and enhanced serotonin actions lead to: increased evoked pain; reduced descending inhibitory pain control by the brain; and promotion of central sensitization [11].

Tapentadol is an innovative analgesic drug, which is currently the only member of the new $\mu$-opioid receptor (MOR)-noradrenaline reuptake inhibitor (NRI) class. This molecule presents both a MOR activity, although lower than that of morphine, and the ability to inhibit the reuptake of noradrenaline [7]. Extensive preclinical data reveal 


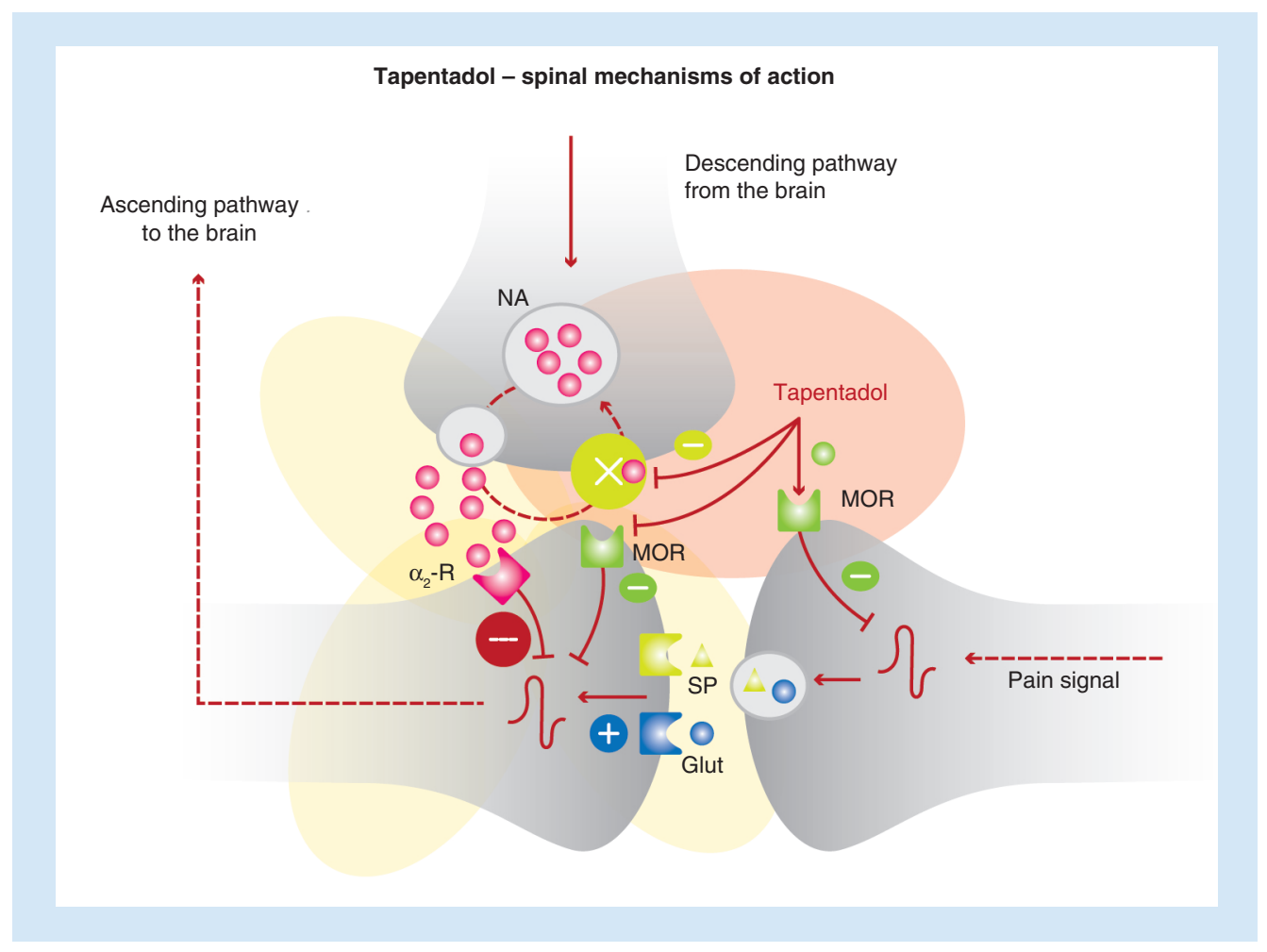

Figure 2. Spinal mechanisms of action of tapentadol.

MOR: $\mu$-opioid receptor; NA: Noradrenaline.

an efficacy of tapentadol equal to that of morphine, but with a major noradrenergic component in behavioral and neuronal measures of nerve injury, arthritis and cancer-induced bone pain [12,13]. Remarkably, there is a positive synergy between the MOR and NRI actions and the ability to modulate central sensitization. Indeed, the MOR action inhibits pain messages at the spinal cord level and in the brain, while the NRI component provides a powerful inhibitory action on spinal overactivity. These properties have direct relevance to clinical efficacy and practice [14].

\section{Does 'strong analgesic' equal 'strong opioid'?}

Tapentadol is characterized by a dual mechanism of action, namely MOR agonism and NRI [12,13]. Therefore, this molecule enhances inhibitory pain control and reduces ascending pain messages, providing a synergic analgesic effect (Figure 2). In terms of pharmacokinetics, tapentadol has a very low potential of interaction and its metabolites do not present any relevant biological activity.

In vivo, these properties translate into a broad analgesic efficacy in different types of pain: tapentadol presents a 50-fold lower MOR affinity, but an analgesic potency close to morphine (Figure 3) [12,13,15]. Remarkably, the relative contribution of the two mechanisms of action is dependent on the specific pain type: MOR agonism predominantly mediates tapentadol antinociceptive effects, whereas NRI activity predominantly mediates its antihypersensitivity effects [16].

Recently, the concept of ' $\mu$-load' has been introduced, with respect to tapentadol [17]. More specifically, the percentage contribution of the MOR and the NRI component to analgesia and to adverse effects was estimated by applying standard drug-receptor theory and novel approaches to the analysis of in vitro and in vivo data. Overall, the percentage contribution of the MOR component to the adverse effect magnitude relative to a pure/classical $\mu$-opioid at equianalgesia (termed the $\mu$-load of tapentadol) was $\leq 40 \%$, compared with pure MOR agonists, which have, by definition, a $\mu$-load of $100 \%$. This reduced $\mu$-load can translate into a more favorable tolerability profile of tapentadol compared with strong classical opioids in terms of reduced incidence of constipation, respiratory depression and other MOR-related side effects. 

in acute nociceptive pain (mouse)

(A) Tail flick model, mouse, iv.

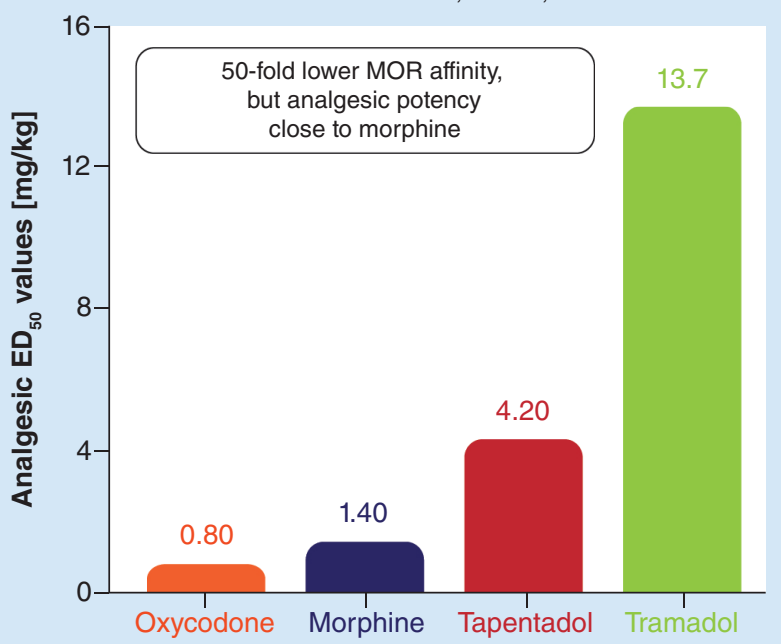

Tapentadol - high potency in inflammatory pain (rat)

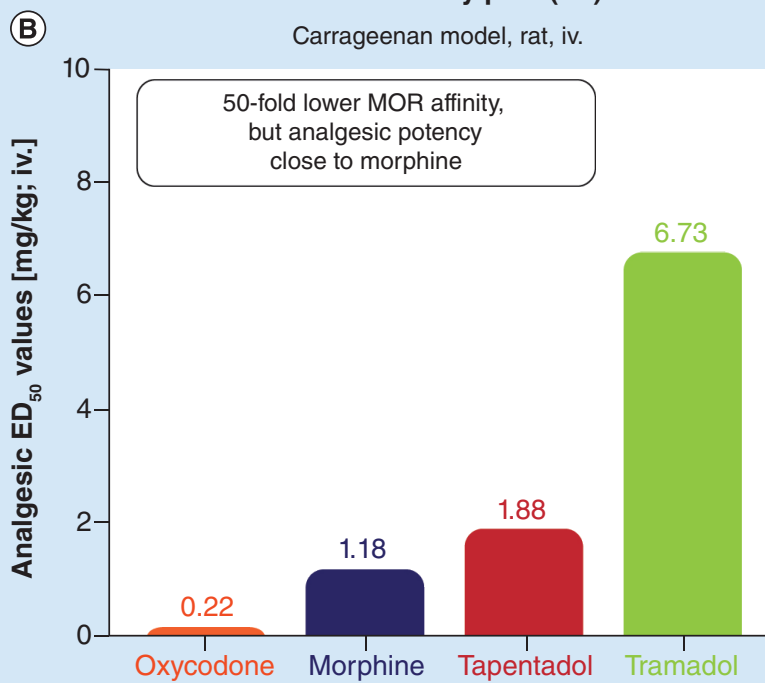

Tapentadol in neuropathic pain models -
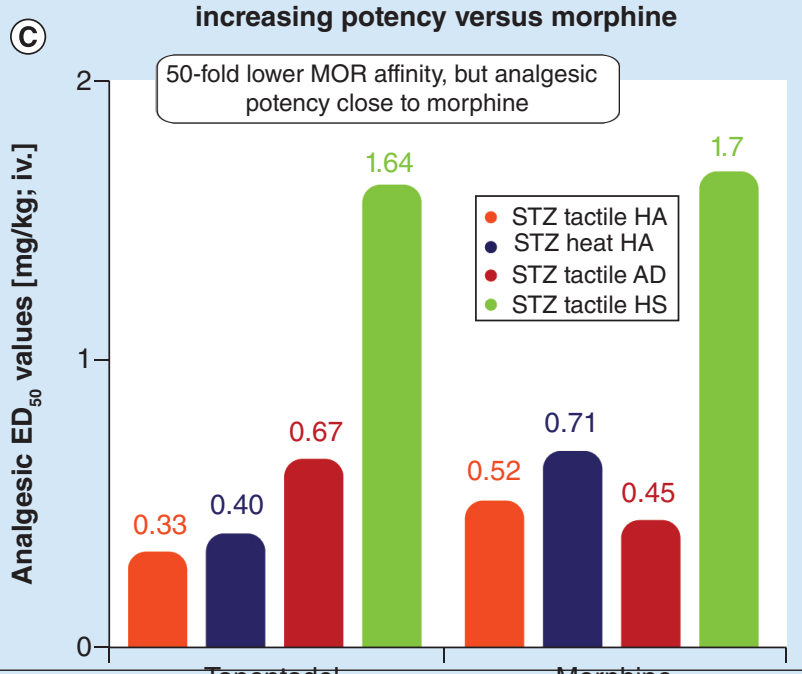

Tapentadol

Morphine

Figure 3. Potency of tapentadol in different models of pain. (A) Acute nociceptive pain. (B) Inflammatory pain. (C) 


\section{Table 1. Tests applicable in clinical practice to identify peripheral and central sensitization.}

\begin{tabular}{|c|c|c|c|}
\hline Test & Nature & Action & Patients' reaction if positive \\
\hline Heat allodynia & $\begin{array}{l}\text { Normally nonpainful heat stimuli evoke } \\
\text { pain }\end{array}$ & $\begin{array}{l}\text { Touch skin with object at } 40^{\circ} \mathrm{C} \text { (metal } \\
\text { roller, glass of water) }\end{array}$ & Heat allodynia \\
\hline Mechanical dynamic allodynia & $\begin{array}{l}\text { Normally nonpainful light stroking } \\
\text { stimuli on skin evoke pain }\end{array}$ & $\begin{array}{l}\text { Stroking skin with painter's brush, } \\
\text { cotton swab or gauze }\end{array}$ & $\begin{array}{l}\text { Sharp burning superficial pain in the } \\
\text { primary affected zone, spreading into } \\
\text { unaffected skin areas (secondary zone) }\end{array}$ \\
\hline $\begin{array}{l}\text { Mechanical punctate or pinprick } \\
\text { hyperalgesia }\end{array}$ & $\begin{array}{l}\text { Normally painful stimuli evoke } \\
\text { increased pain }\end{array}$ & $\begin{array}{l}\text { Manual pricking of the skin with a } \\
\text { sterile pin or monofilament }\end{array}$ & $\begin{array}{l}\text { Sharp superficial pain in the primary } \\
\text { affected zone, spreading into } \\
\text { unaffected skin areas (secondary zone) }\end{array}$ \\
\hline Temporal summation & $\begin{array}{l}\text { Repetitive application of identical single } \\
\text { noxious stimuli is perceived as } \\
\text { increasing pain sensation (wind-up-like } \\
\text { pain) }\end{array}$ & $\begin{array}{l}\text { Pricking the skin with sterile pin at }<3 \mathrm{~s} \\
\text { intervals for } 30 \mathrm{~s}\end{array}$ & $\begin{array}{l}\text { Sharp superficial pain of increasing } \\
\text { intensity }\end{array}$ \\
\hline
\end{tabular}

\section{Chronic musculoskeletal pain: from "theory' to clinical diagnosis}

Recent developments, based on studies including imaging, for example, functional magnetic resonance, have highlighted the importance of neuronal sensitization by chemical mediators as well as roles for non-neuronal cells - for instance, macrophages/microglia - in the process of peripheral sensitization and pain amplification [18,19]. Indeed, chronic pain after arthritis, nerve injury, cancer and chemotherapy can be associated with local chronic neuroinflammation; patients with peripheral sensitization may show an enhanced response to heat (allodynia and hyperalgesia) [20]. This finding has important diagnostic consequences in clinical practice, since it can help a physician identify peripheral sensitization at the bedside, for example, by touching the patient with a warm (approximately $40^{\circ} \mathrm{C}$ ) object (Table 1 ). Moreover, the presence of heat hypersensitivity can help determine the selection of optimal therapy, for instance by using drugs able to target this process (e.g., topical capsaicin).

Other semiquantitative bed-side diagnostic tests - simpler and less expensive than the gold standard, in other words, quantitative sensory testing - are useful in clinical practice to identify central sensitization, namely mechanical allodynia, punctate hyperalgesia and temporal summation (Table 1). Other characteristics of central sensitization include loss of proportionality between stimulus and clinical response, widespread pain, and maladaptive psychological responses to pain.

The application of these tests in clinical practice can enable a physician to correctly recognize central sensitization, and plan a mechanism-based therapy [21]. For instance, it is now well considered that a subgroup of patients with OA present with central sensitization and neuropathic pain components: pain therapy should aim to address these components (Figure 4) [22].

\section{The role of the opioid \& noradrenergic components of tapentadol in chronic musculoskeletal pain}

Combining different analgesics with different mechanisms of action is a common strategy in clinical practice; however, this may lead to less convenient schedules of administration and increased burden of adverse events [23]. In this regard, the unique profile of tapentadol makes it especially suitable for the treatment of chronic pain conditions with nociceptive as well as neuropathic components, using a single drug and avoiding complex combinations [24,25].

The efficacy of tapentadol in musculoskeletal pain (OA, back pain) and in oncological pain has been reviewed recently in a series of publications [26-29]. A detailed review of all studies evaluating tapentadol, in its prolongedrelease (PR) formulation, goes beyond the scope of the present report. Overall, clinical data on the efficacy of tapentadol PR are robust, both in clinical trial and 'field-practice' settings. Moreover, treatment with tapentadol has been demonstrated to improve the QoL of patients and their functional recovery, which should be considered among the key goals of analgesic therapy [30]. Remarkably, all these benefits are consistent regardless of the patient and disease characteristics - such as age, gender, weight, severity of baseline pain, importance of the neuropathic component - thus indicating that tapentadol can be a suitable therapeutic option in all patients with chronic pain conditions.

Safety plays a central role in the selection of long-term analgesic therapy [31]. Opioid therapy may be associated with several adverse events, such as undesirable cardiovascular and respiratory effects, gastrointestinal disorders, endocrine complications, psychological problems, impairment of driving ability and risk of abuse [32]. Overall, 


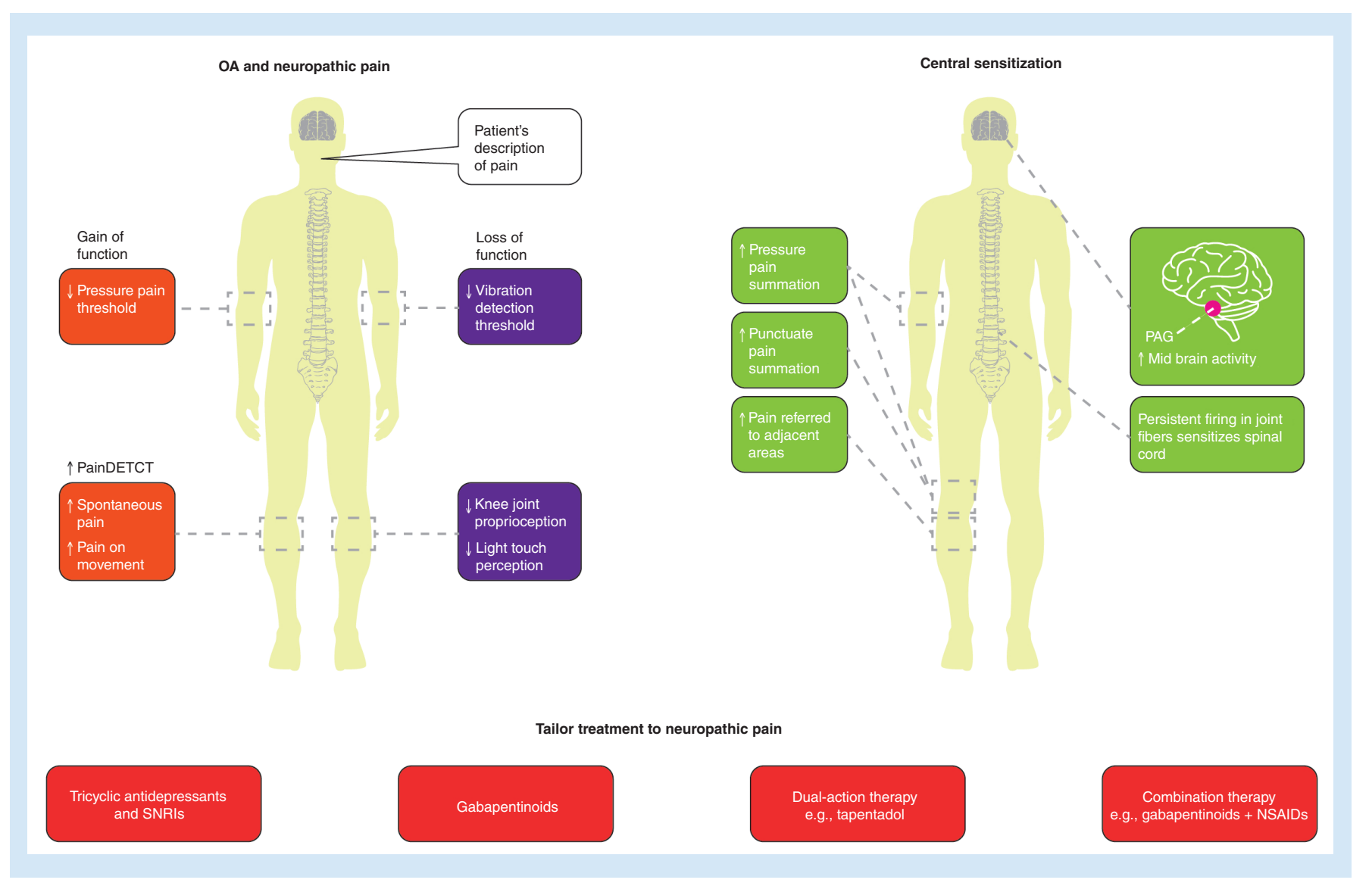

Figure 4. Detecting central sensitization and neuropathic features in musculoskeletal pain syndromes.

Reproduced with permission from [22] (C) Springer Nature (2014).

NSAID: Nonsteroidal anti-inflammatory drug; OA: Osteoarthritis; PAG: Periaqueductal gray; SNRI: Serotonin-norepinephrine reuptake inhibitor.

these effects of opioids are mostly due to the widespread expression of the $\mu$-receptor in neuronal and other tissues in the human body.

Noteworthy, as described above, the $\mu$-load of tapentadol is markedly lower compared with that of classical opioids, therefore resulting in fewer opioid-related adverse effects [33]. The safety of tapentadol has been discussed recently in a comprehensive review, which provides further details and the incidence of specific adverse events [33]. For the purpose of this report, in summary, the long-term safety of tapentadol has been confirmed in several studies [34-36], with specific data collected in a study lasting more than 4 years [35]. Moreover, tapentadol has some advantages with relevance to clinical practice, such as no interaction with warfarin or antidepressant drugs, lack of effect on sex hormones and low abuse potential $[33,37]$. Importantly, tapentadol does not impair the ability to drive [33].

Overall, tapentadol PR represents an effective and safe therapy for chronic painful conditions, supported by a strong mechanistic rationale. Further, given the availability of long-term efficacy and safety data, tapentadol PR should be considered a suitable front-line therapy in this setting.

\section{Peripheral input \& central sensitization: the rationale for topical therapy}

As discussed in a preceding section of this report, peripheral nociceptor hyperactivity mediates peripheral nociceptive and neuropathic pain; it usually also drives the development and maintenance of dysfunctional central processing. Peripheral overactivity causes central hyperexcitability, leading to the establishment of central sensitization (Figure 5) [19,38]. Ion channels play a major role in the process of maintaining central sensitization. In particular, voltage-gated sodium $(\mathrm{NaV})$ channels are responsible for the generation of pathogenic action potentials 


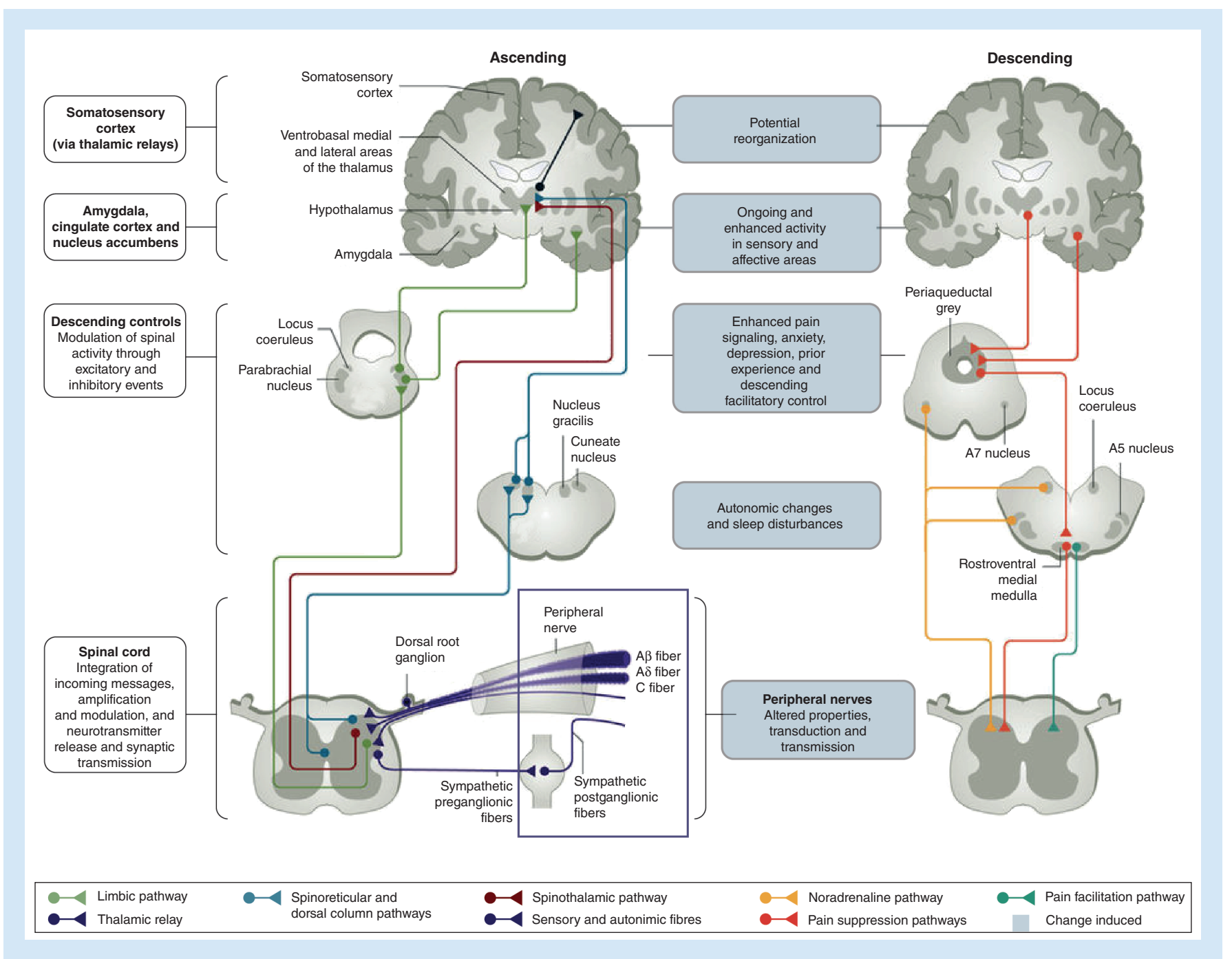

Figure 5. Peripheral sensitization leads to and maintains central sensitization.

in nociceptors $[39,40]$. Targeting these peripheral ion channels may thus prevent painful stimuli from reaching the CNS. However, this strategy may not be effective in all patients [41].

Another key peripheral target for pain relief is the family of the transient receptor potential (TRP) channels. These are expressed by peripheral sensory nerve fibers and act as receptors at cutaneous nerve terminals for sensing temperature changes within specific ranges, and also algogenic chemical ligands [42,43]. TRPV1 (the heat and capsaicin receptor) has been a major target for novel analgesics - however, while oral TRPV1 antagonists, in other words, blockers of TRPV1 receptors can result in analgesia, they also cause unacceptable side effects, and have not been developed for clinical treatment. In contrast, topical use of capsaicin over centuries has been shown to be safe, and effective for the amelioration of pain. Capsaicin is a TRPV1 agonist and is the natural ingredient in chilli peppers that gives them their hot pungency. The mechanism of action of topical capsaicin for pain relief is very different to oral drugs which block TRPV1, as described below.

Topical agents may be preferable to systemic therapies in certain respects, for example, localized action, and low systemic absorption can avoid issues associated with oral or intravenous routes, such as gastric disturbances, variable serum concentrations, and result in a lower risk of drug-drug interactions [44,45]. Two topical treatments are currently licensed by the EMA for peripheral neuropathic pain: lidocaine $700 \mathrm{mg}$ medicated plaster (lidocaine $5 \%$ plaster) for post-herpetic neuralgia (PHN) only, and the capsaicin $179 \mathrm{mg}$ cutaneous patch (capsaicin 8\% patch) for all types of peripheral neuropathic pain. 


\section{Topical treatment for peripheral neuropathic pain: focus on capsaicin}

Capsaicin activates the TRPV1 receptor on cutaneous small nerve fibers, and hence its topical application causes a burning sensation and erythema (redness) in normal human skin [46]. TRPV1 expression changes in nociceptors in some chronic inflammatory and neuropathic pain conditions, and is the foremost therapeutic target in the TRP receptor family for pain and hypersensitivity [47].

Peripheral neuropathic hypersensitivity is mediated by diverse mechanisms, including increased expression of TRPV1 or other key ion channels in surviving nerve fibers, aberrant re-innervation and collateral sprouting [48]. A high-concentration capsaicin $8 \%$ patch $\left(\right.$ Qutenza $\left.^{\mathrm{TM}}\right)$ is licensed for chronic neuropathic pain treatment in the EU and the USA [48]. A single 30-60-min application in patients with neuropathic pain was shown to result in effective pain relief for up to 3 months or longer. Topical capsaicin acts by attenuating cutaneous hypersensitivity and reducing pain by a process described as 'defunctionalization' of nociceptor fibers, which is due to a number of effects including temporary loss of membrane potential, inability to transport neurotrophic factors leading to altered phenotype, and reversible retraction of epidermal and dermal nerve fiber terminals [48]. This defunctionalization is reversible; the affected nerve fibers may then regrow, usually during the 3 months after the capsaicin $8 \%$ patch application. The patch may be re-applied three monthly, if needed. In some cases, pain relief persists beyond 3 months after patch application. It has been reported that the regenerating nerve fibers, following capsaicin $8 \%$ patch application, may show improved density and phenotype, for example, in patients who had chemotherapyinduced painful neuropathy, and were now in remission [49]. Capsaicin $8 \%$ patch does not induce clinically relevant systemic exposure of capsaicin, thus limiting the risk of systemic adverse events, and does not affect function of large sensory nerve fibers (as TRPV1 is expressed primarily in nociceptors).

The capsaicin $8 \%$ patch has proved to be an effective and safe treatment in several clinical trials and 'field-practice' studies, for multiple painful neuropathy conditions [50-62]. In the recent randomized ELEVATE study, conducted in more than 500 patients with peripheral neuropathic pain, the capsaicin $8 \%$ patch was shown to be noninferior to pregabalin for $\mathrm{a} \geq 30 \%$ mean decrease of the pain score on a numeric pain rating scale (from baseline to week 8 [55.7 vs 54.5\%; OR: 1.03 [95\% CI: $0.72-1.50]$ ] [58]. The proportion of patients achieving optimal therapeutic effect at week 8 was $52.1 \%$ for the capsaicin $8 \%$ patch compared with $44.8 \%$ for pregabalin, and the median time-to-onset of pain relief was significantly shorter for capsaicin 8\% patch versus pregabalin (HR: 1.68 [95\% CI: 1.35-2.08]; $\mathrm{p}<0.0001$; Figure 6) [58]. Importantly, the reduction of the area and intensity of mechanical allodynia was significantly superior to pregabalin (Figure 7) [58,59]. Adverse events were mainly of mild-to-moderate severity in both arms but resulted in treatment discontinuation only with pregabalin; these were reported only at the time of application for capsaicin $8 \%$ patch, but over the entire duration of treatment with pregabalin. Treatment satisfaction was also greater with the capsaicin $8 \%$ patch.

On this evidence, the capsaicin $8 \%$ patch may be effective and the treatment of choice in selected patients, and it may also be effective in cases where other treatments have failed.

\section{Topical treatment for peripheral neuropathic pain: focus on lidocaine}

Lidocaine is known to act as a local analgesic by the partial and selective inhibition of voltage-gated sodium channels expressed by small sensory nerve fibers (unmyelinated C fibers and small myelinated A $\delta$ fibers) [63]; this action is particularly relevant when there are damaged or dysfunctional fibers. This pharmacological action stabilizes the neuronal membrane potential, resulting in a reduction of ectopic discharges, thus providing an analgesic effect without local anesthesia [63].

The lidocaine 5\% plaster is currently approved for the treatment of PHN [61]. In its 5\% plaster formulation, lidocaine has shown efficacy, associated with good short- and long-term tolerability, with a very low systemic uptake (3\%), and minimal risk for systemic adverse events or pharmacological interactions [63]. This good safety profile is of particular relevance in clinical practice, since the majority of the PHN patients are elderly, and present with frequent comorbidities and/or are taking a number of other medications. Moreover, the use of a plaster can enhance treatment adherence [44,64]. Remarkably, topical lidocaine is now recommended by major international guidelines as a first- or second-line treatment for localized neuropathic pain (Table 2) [65-67].

The efficacy and safety of lidocaine 5\% plaster have been evaluated comprehensively [63]. In an open-label, noninferiority trial in patients with PHN or diabetic polyneuropathy (DPN), the lidocaine 5\% plaster was more effective than pregabalin in reducing pain in patients with $\mathrm{PHN}$, and was associated with greater satisfaction among patients and an improved QoL compared with pregabalin for both indications [68]. In the 3-year extension phase of the study, lidocaine 5\% plaster proved to be effective and well-tolerated in PHN patients [69]. In a very recent 


\begin{tabular}{|c|c|c|}
\hline \multirow[t]{2}{*}{ Parameters } & \multicolumn{2}{|c|}{ Full analysis set } \\
\hline & Qutenza & Pregabalin \\
\hline $\begin{array}{l}\text { Primary end point }{ }^{\dagger} \\
\text { Responders } \\
\text { (total population) }\end{array}$ & $\begin{array}{c}55.7 \% \\
n=282\end{array}$ & $\begin{array}{c}54.5 \% \\
n=277\end{array}$ \\
\hline \begin{tabular}{|l|} 
Responders \\
(PNI subset)
\end{tabular} & $\begin{array}{c}53.4 \% \\
n=146\end{array}$ & $\begin{array}{c}40.9 \% \\
n=137\end{array}$ \\
\hline
\end{tabular}

Time to onset of pain relief

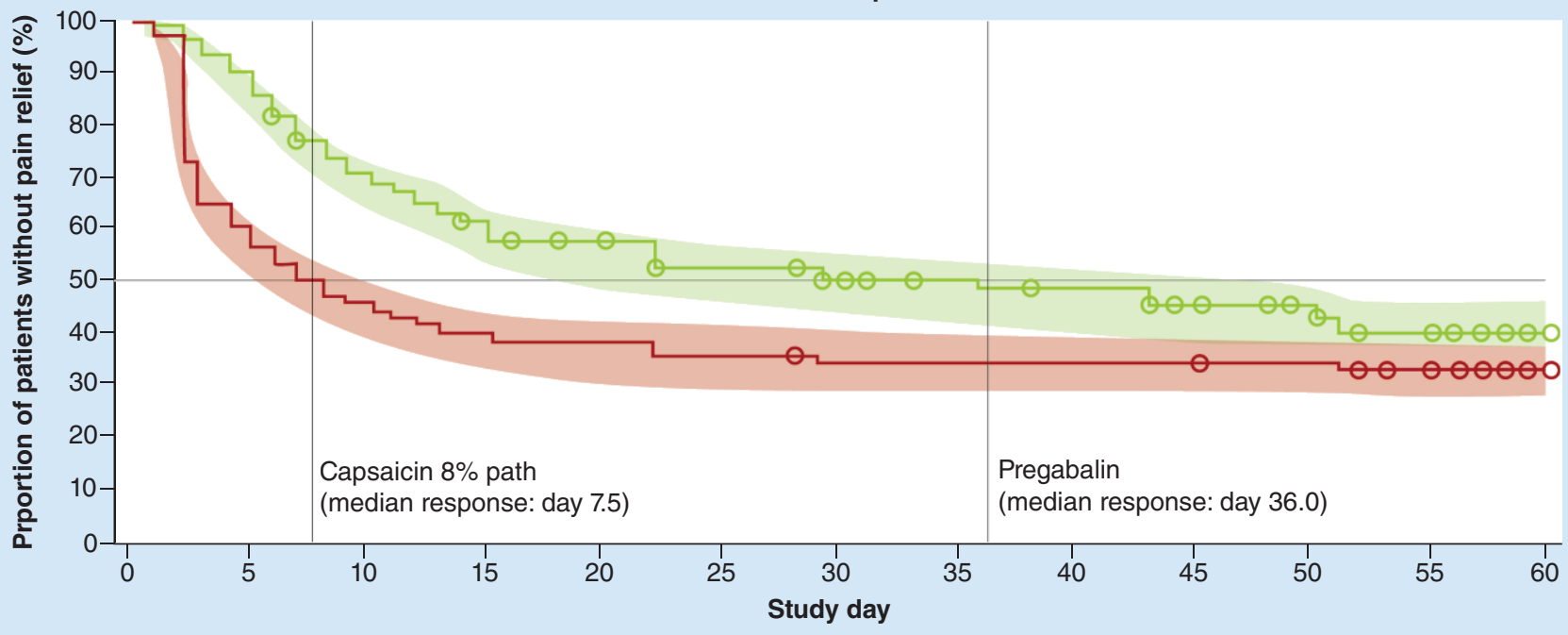

Figure 6. Key efficacy outcomes of the ELEVATE study.

${ }^{\dagger}$ Capsaicin $8 \%$ path was noninferior versus pregabalin (difference: $1.2 \%$; odds ratio: 1.03 ; 95\% Cl: 0.71-1.50).

PNI: Posttraumatic/postsurgical nerve injury.

Reproduced with permission from [58], (c) Haanpää et al., licensed with CC BY-NC-ND 4.0.

Table 2. Recommendations of major guidelines for localized neuropathic pain.

Guidelines/guidance Last update

Neuropathic Pain Special Interest Group 2015

of the International Association for the

Study of Pain

European Federation of Neurological

Societies

2010

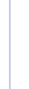

First-line recommendation

- Tricyclic antidepressant

- Gabapentin

- Pregabalin

- Topical lidocaine in frail and elderly patients

- Gabapentin

- Pregabalin

- Tricyclic antidepressants

- Lidocaine-medicated plaster in PHN patients

American Academy of Neurology
- Gabapentin

- Lidocaine plaster

- Oxycodone or morphine

- Pregabalin

- Tricyclic antidepressants
Second-line recommendation

- Tramadol

- Capsaicin

- Topical lidocaine

- Opioid analgesics (third line)

- Capsaicin

- Opioids

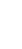

\section{- Aspirin in cream or ointment}

- Capsaicin (topical)

- Methylprednisolone (Intrathecal)

PHN: Post-herpetic neuralgia.

Data taken from $[65,67]$.

lidocaine 5\% plaster clinical study conducted in Italy in 130 patients with different painful conditions, 32\% of whom had their pain not controlled by systemic analgesics and/or experienced unacceptable adverse events, 5\% of these patients reported complete pain relief without any systemic therapy, and $38 \%$ of patients reduced their analgesic drug consumption [70]. The overall incidence of adverse events was $16.6 \%$, but all events were local and 


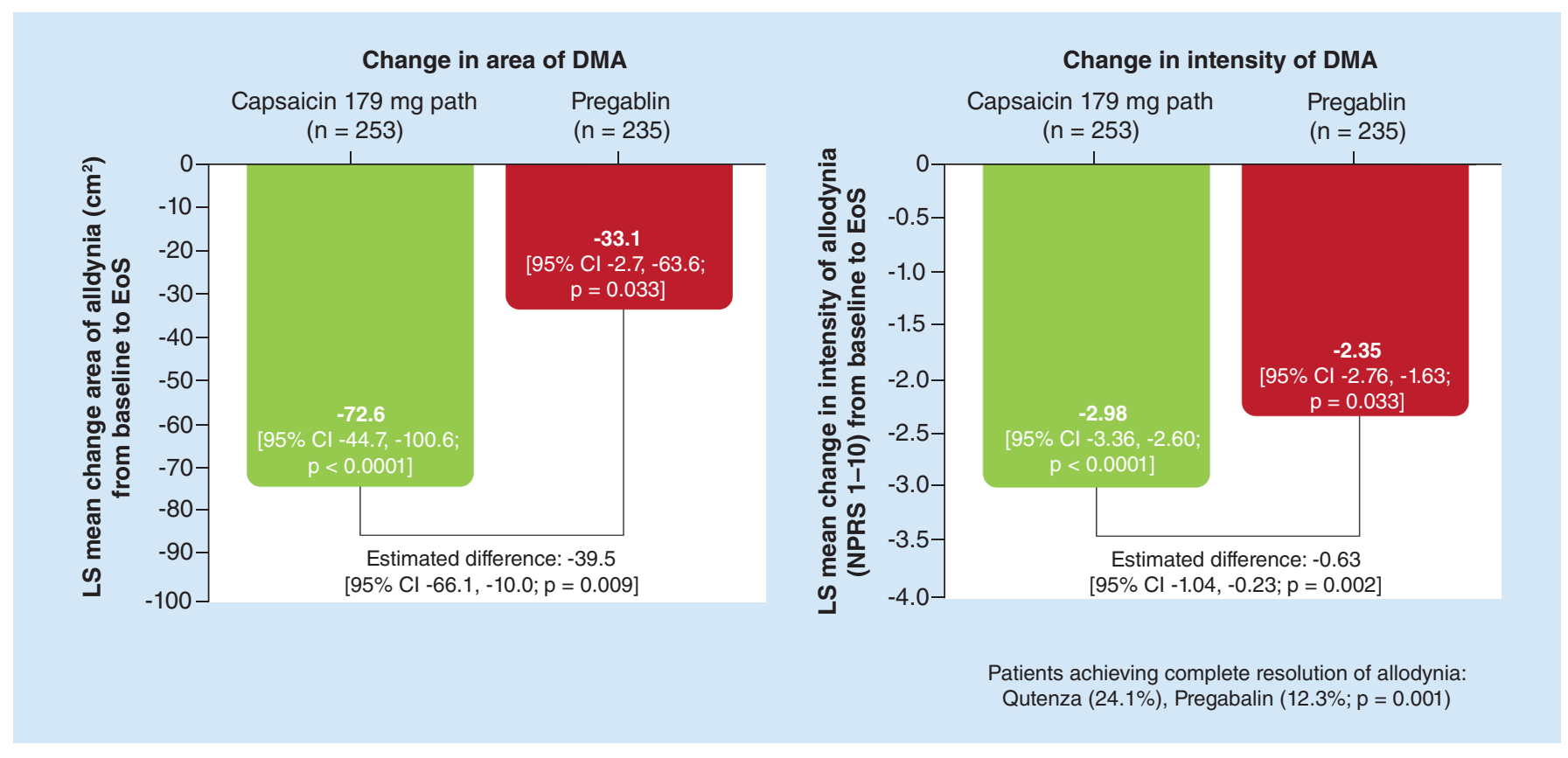

Figure 7. Efficacy of capsaicin $8 \%$ patch and pregabalin on dynamic mechanical allodynia in the ELEVATE study.

Reproduced with permission from [58], (c) Haanpää et al., licensed with CC BY-NC-ND 4.0.

Cl: Confidence interval; DMA: Dynamic mechanical allodynia; EoS: End of study; LS: Least squares.

transient. Moreover, in another 'field-practice' study, lidocaine 5\% plaster was associated with a reduced need for other oral analgesics in elderly patients [71].

In line with the above evidence, it has been suggested that the lidocaine 5\% plaster should be more strongly recommended for treating localized neuropathic pain such as in PHN, either as one component of a multimodal approach or as monotherapy [72].

\section{Conclusion}

There have been major advances in the understanding and management of chronic pain over the last few years. Basic and clinical research have guided the use of analgesic drugs, underpinned by a well-grounded rationale of their pharmacological actions, to target specific mechanisms of the pathophysiology of pain. The use of such drugs - including tapentadol, capsaicin and lidocaine - in clinical practice can lead to marked and sustained relief from chronic pain, and thereby address a global unmet need, with major improvements in the quality of life of patients.

Author contributions

This article is based on a symposium hosted by Grunenthal entitled 'Science of relief' held in May 2019. The manuscript was developed based on presentations made by the authors during that session. All authors reviewed and revised the manuscript, and agreed on the final version.

Financial \& competing interests disclosure

TM Tzschentke is an employee of Grunenthal. The authors have no other relevant affiliations or financial involvement with any organization or entity with a financial interest in or financial conflict with the subject matter or materials discussed in the manuscript apart from those disclosed.

Third party medical writing support was supplied L Giacomelli and A Shah of Polistidium supported by Grunenthal.

This work is licensed under the Attribution-NonCommercial-NoDerivatives 4.0 Unported License. To view a copy of this license, visit http://creativecommons.org/licenses/by-nc-nd/4.0/ 


\section{References}

Papers of special note have been highlighted as: • of interest; $\bullet \bullet$ of considerable interest

1. 'Disposizioni per garantire l'accesso alle cure palliative e alla terapia del dolore' (2019). www.parlamento.it/parlam/leggi/10038l.htm

2. Montes A, Aguilar JL, Benito MC, Caba F, Margarit C; Acute Pain Group of the Spanish Pain Society (SED). Management of postoperative pain in Spain: a nationwide survey of practice. Acta Anaesthesiol. Scand. 61(5), 480-491 (2017).

3. Fang LY, Xu YC, Lin DN, Jin JF, Yan M. Attitude and intention regarding pain management among Chinese nursing students: a cross-sectional questionnaire survey. Pain Manag. Nurs. 18(4), 250-259 (2017).

4. Shoqirat N, Mahasneh D, Al-Khawaldeh O, Singh C. Postoperative patients in Jordan: pain prevalence, characteristics, beliefs, and satisfaction. Pain Manag. Nurs. 20(3), 239-244 (2019).

5. Breivik H, Collett B, Ventafridda V, Cohen R, Gallacher D. Survey of chronic pain in Europe: prevalence, impact on daily life, and treatment. Eur. J. Pain 10(4), 287-333 (2006).

6. Dureja GP, Jain PN, Shetty N et al. Prevalence of chronic pain, impact on daily life, and treatment practices in India. Pain Pract. 14(2), E51-E62 (2014).

7. Dickenson AH, Kress HG. Tapentadol: a new option for the treatment of cancer and noncancer pains. J. Pain Res. 12, 1509-1511 (2019).

-• Short paper illustrating the role of tapentadol in clinical practice.

8. Sprenger C, Finsterbusch J, Büchel C. Spinal cord-midbrain functional connectivity is related to perceived pain intensity: a combined spino-cortical fMRI study. J. Neurosci. 35(10), 4248-4257 (2015).

9. Arendt-Nielsen L, Morlion B, Perrot S et al. Assessment and manifestation of central sensitisation across different chronic pain conditions. Eur. J. Pain 22, 216-241 (2018).

-. Landmark paper discussing the importance of central sensitization.

10. Bannister K, Bee LA, Dickenson AH. Preclinical and early clinical investigations related to monoaminergic pain modulation. Neurotherapeutics 6(4), 703-712 (2009).

11. Youssef AM, Macefield VG, Henderson LA. Cortical influences on brainstem circuitry responsible for conditioned pain modulation in humans. Hum. Brain Mapp. 37(7), 2630-2644 (2016).

12. Tzschentke TM, Christoph T, Kögel BY. The mu-opioid receptor agonist/noradrenaline reuptake inhibition (MOR-NRI) concept in analgesia: the case of tapentadol. CNS Drugs 28(4), 319-329 (2014).

-• Discusses the dual mechanism of action of tapentadol and its implications.

13. Tzschentke TM, Christoph T, Kögel B et al. (-)-(1R,2R)-3-(3-dimethylamino-1-ethyl-2-methyl-propyl)-phenol hydrochloride (tapentadol $\mathrm{HCl}$ ): a novel mu-opioid receptor agonist/norepinephrine reuptake inhibitor with broad-spectrum analgesic properties. $J$. Pharmacol. Exp. Ther. 323(1), 265-276 (2007).

14. Langford RM, Knaggs R, Farquhar-Smith P, Dickenson AH. Is tapentadol different from classical opioids? A review of the evidence. $B r$. J. Pain 10(4), 217-221 (2016).

15. Tzschentke TM, Christoph T, Schröder W et al. Tapentadol: mit zwei Mechanismen in einem Molekül wirksam gegen nozizeptive und neuropathische Schmerzen. Schmerz 25, 19-25 (2011).

16. Schröder W, Vry JD, Tzschentke TM, Jahnel U, Christoph T. Differential contribution of opioid and noradrenergic mechanisms of tapentadol in rat models of nociceptive and neuropathic pain. Eur. J. Pain 14(8), 814-821 (2010).

17. Raffa RB, Elling C, Tzschentke TM. Does 'strong analgesic' equal 'strong opioid'? Tapentadol and the concept of ' $\mu$-load'. Adv. Ther. 35(10), 1471-1484 (2018).

- Recent manuscript presenting the novel concept of $\mu$-load.

18. Kutch JJ, Ichesco E, Hampson JP et al.; MAPP Research Network. Brain signature and functional impact of centralized pain: a multidisciplinary approach to the study of chronic pelvic pain (MAPP) network study. Pain 158(10), 1979-1991 (2017).

19. Ji RR, Chamessian A, Zhang YQ. Pain regulation by non-neuronal cells and inflammation. Science 354(6312), 572-577 (2016).

20. Costigan M, Scholz J, Woolf CJ. Neuropathic pain: a maladaptive response of the nervous system to damage. Annu. Rev. Neurosci. 32, 1-32 (2009).

21. Baron R. Mechanisms of disease: neuropathic pain - a clinical perspective. Nat. Clin. Pract. Neurol. 2(2), $95-106$ (2006).

22. Thakur M, Dickenson AH, Baron R. Osteoarthritis pain: nociceptive or neuropathic? Nat. Rev. Rheumatol. 10(6), 374-380 (2014).

23. Raffa RB, Pergolizzi JV Jr, Tallarida RJ. The determination and application of fixed-dose analgesic combinations for treating multimodal pain. J. Pain 11(8), 701-709 (2010).

24. Tzschentke TM, Jahnel U, Kogel B et al. Tapentadol hydrochloride: a next-generation, centrally acting analgesic with two mechanisms of action in a single molecule. Drugs Today (Barc.) 45(7), 483-496 (2009).

25. Romualdi P, Grilli M, Canonico PL, Collino M, Dickenson AH. Pharmacological rationale for tapentadol therapy: a review of new evidence. J. Pain Res. 12, 1513-1520 (2019). 
26. Coluzzi F, Polati E, Freo U, Grilli M. Tapentadol: an effective option for the treatment of back pain. J. Pain Res. 12, 1521-1528 (2019).

27. Kress HG, Coluzzi F. Tapentadol in the management of cancer pain: current evidence and future perspectives. J. Pain Res. 12, 1553-1560 (2019).

28. Freo U, Romualdi P, Kress HG. Tapentadol for neuropathic pain: a review of clinical studies. J. Pain Res. 12, 1537-1551 (2019).

29. Rinonapoli G, Coaccioli S, Panella L. Tapentadol in the treatment of osteoarthritis: pharmacological rationale and clinical evidence. J. Pain Res. 12, 1529-1536 (2019).

30. Panella L, Rinonapoli G, Coaccioli S. Where should analgesia lead to? Quality of life and functional recovery with tapentadol. J. Pain Res. 12, 1561-1567 (2019).

31. Argoff CE, Albrecht P, Irving G, Rice F. Multimodal analgesia for chronic pain: rationale and future directions. Pain Med. 10(Suppl. 2), S53-S66 (2009).

32. Els C, Jackson TD, Kunyk D et al. Adverse events associated with medium- and long-term use of opioids for chronic non-cancer pain: an overview of Cochrane Reviews. Cochrane Database Syst. Rev. 10, CD012509 (2017).

33. Polati E, Canonico PL, Schweiger V, Collino M. Tapentadol: an overview of the safety profile. J. Pain Res. 12, 1569-1576 (2019).

34. Wild JE, Grond S, Kuperwasser B et al. Long-term safety and tolerability of tapentadol extended release for the management of chronic low back pain or osteoarthritis pain. Pain Pract. 10(5), 416-427.

35. Finco G, Mura P, Musu M. Long-term oral tapentadol prolonged-release for the treatment of refractory chronic low back pain: a single-center, observational study. Minerva Med. (2018) (In Press).

36. Baron R, Kern U, Müller M, Dubois C, Falke D, Steigerwald I. Effectiveness and tolerability of a moderate dose of tapentadol prolonged release for managing severe, chronic low back pain with a neuropathic component: an open-label continuation arm of a randomized Phase IIIb study. Pain Pract. 15(5), 471-486 (2015).

37. Gomes T, Tadrous M, Mamdani MM, Paterson JM, Juurlink DN. The burden of opioid-related mortality in the United States. JAMA Netw. Open 1(2), e180217 (2018).

38. Gracely RH, Lynch SA, Bennett GJ. Painful neuropathy: altered central processing maintained dynamically by peripheral input. Pain 51(2), 175-194 (1992).

- Landmark study highlighting the importance of peripheral input on central processing.

39. Nau C, Leipold E. Voltage-gated sodium channels and pain (2019). www.degruyter.com/view/j/nf.2017.23.issue-3/nf-2017-A017/nf-2017-A017.xml

40. Dib-Hajj SD1, Waxman SG. Diversity of composition and function of sodium channels in peripheral sensory neurons. Pain 156(12), 2406-2407 (2015).

41. Dickenson AH, Patel R. Sense and sensibility - logical approaches to profiling in animal models. Pain 159(7), 1426-1428 (2018).

42. Vay L, Gu C, McNaughton PA. The thermo-TRP ion channel family: properties and therapeutic implications. Br. J. Pharmacol. 165(4), 787-801 (2012).

43. Kremeyer B, Lopera F, Cox JJ et al. A gain-of-function mutation in TRPA1 causes familial episodic pain syndrome. Neuron 66(5), 671-680 (2010).

44. Sommer C, Cruccu G. Topical treatment of peripheral neuropathic pain: applying the evidence. J. Pain Symptom Manage. 53(3), 614-629 (2017).

45. Allegri M, Baron R, Hans G et al. A pharmacological treatment algorithm for localized neuropathic pain. Curr. Med. Res. Opin. 32, $377 \mathrm{e} 384$ (2016).

46. McKemy DD. How cold is it? TRPM8 and TRPA1 in the molecular logic of cold sensation. Mol. Pain 1, 16 (2005).

47. Facer P, Casula MA, Smith GD et al. Differential expression of the capsaicin receptor TRPV1 and related novel receptors TRPV3, TRPV4 and TRPM8 in normal human tissues and changes in traumatic and diabetic neuropathy. BMC Neurol. 7, 11 (2007).

48. Anand P, Bley K. Topical capsaicin for pain management: therapeutic potential and mechanisms of action of the new high-concentration capsaicin 8\% patch. Br. J. Anaesth. 107(4), 490-502 (2011).

-. Key paper on the use of capsaicin $8 \%$ in the treatment of neuropathic pain.

49. Anand P, Elsafa E, Privitera R et al. Rational treatment of chemotherapy-induced peripheral neuropathy with capsaicin $8 \%$ patch: from pain relief towards disease modification. J. Pain Res. 12, 2039-2052 (2019).

50. Backonja M, Wallace MS, Blonsky ER et al.; NGX-4010 C116 Study Group. NGX-4010, a high-concentration capsaicin patch, for the treatment of postherpetic neuralgia: a randomised, double-blind study. Lancet Neurol. 7(12), 1106-1112 (2008).

51. Irving GA, Backonja MM, Dunteman E et al.; NGX-4010 C117 Study Group. A multicenter, randomized, double-blind, controlled study of NGX-4010, a high-concentration capsaicin patch, for the treatment of postherpetic neuralgia. Pain Med. 12(1), 99-109 (2011).

52. Webster LR, Tark M, Rauck R, Tobias JK, Vanhove GF. Effect of duration of postherpetic neuralgia on efficacy analyses in a multicenter, randomized, controlled study of NGX-4010, an $8 \%$ capsaicin patch evaluated for the treatment of postherpetic neuralgia. $B M C$

Neurol. 10, 92 (2010). 
53. Webster LR, Malan TP, Tuchman MM, Mollen MD, Tobias JK, Vanhove GF. A multicenter, randomized, double-blind, controlled dose finding study of NGX-4010, a high-concentration capsaicin patch, for the treatment of postherpetic neuralgia. J. Pain 11(10), 972-982 (2010).

54. Clifford DB, Simpson DM, Brown S et al:; NGX-4010 C119 Study Group. A randomized, double-blind, controlled study of NGX-4010, a capsaicin $8 \%$ dermal patch, for the treatment of painful HIV-associated distal sensory polyneuropathy. J. Acquir. Immune Defic. Syndr. 59(2), 126-133 (2012).

55. Simpson DM, Brown S, Tobias J; NGX-4010 C107 Study Group. Controlled trial of high-concentration capsaicin patch for treatment of painful HIV neuropathy. Neurology 70(24), 2305-2313 (2008).

56. Simpson DM, Robinson-Papp J, Van J et al. Capsaicin $8 \%$ patch in painful diabetic peripheral neuropathy: a randomized, double-blind, placebo-controlled study. J. Pain. 18(1), 42-53 (2017).

57. Gálvez R, Navez ML, Moyle G et al. Capsaicin 8\% patch repeat treatment in nondiabetic peripheral neuropathic pain: a 52-week, open-label, single-arm, safety study. Clin. J. Pain. 33(10), 921-931 (2017).

58. Haanpää M, Cruccu G, Nurmikko TJ et al. Capsaicin $8 \%$ patch versus oral pregabalin in patients with peripheral neuropathic pain. Eur. J. Pain 20(2), 316-328 (2016).

59. Cruccu G, Nurmikko TJ, Ernault E, Riaz FK, McBride WT, Haanpää M. Superiority of capsaicin $8 \%$ patch versus oral pregabalin on dynamic mechanical allodynia in patients with peripheral neuropathic pain. Eur. J. Pain 22(4), 700-706 (2018).

60. Mankowski C, Poole CD, Ernault E et al. Effectiveness of the capsaicin $8 \%$ patch in the management of peripheral neuropathic pain in European clinical practice: the ASCEND study. BMC Neurol. 17(1), 80 (2017).

61. Maihofner C, Heskamp ML. Prospective, non-interventional study on the tolerability and analgesic effectiveness over 12 weeks after a single application of capsaicin $8 \%$ cutaneous patch in 1044 patients with peripheral neuropathic pain: first results of the QUEPP study. Curr. Med. Res. Opin. 29(6), 673-683 (2013).

62. Hansson P, Jensen TS, Kvarstein G, Strömberg M. Pain-relieving effectiveness, quality of life and tolerability of repeated capsaicin $8 \%$ patch treatment of peripheral neuropathic pain in Scandinavian clinical practice. Eur. J. Pain 22(5), 941-950 (2018).

63. Navez ML, Monella C, Bösl I, Sommer D, Delorme C. $5 \%$ lidocaine medicated plaster for the treatment of postherpetic neuralgia: a review of the clinical safety and tolerability. Pain Ther. 4(1), 1-15 (2015).

64. Sabatowski R, Bösl I, König S, Buchheister B, Meier T, Baron R. Treatment of postherpetic neuralgia with 5\% lidocaine medicated plaster in elderly patients - subgroup analyses from three European clinical trials. Curr. Med. Res. Opin. 33(3), 595-603 (2017).

65. Finnerup NB, Attal N, Haroutounian S et al. Pharmacotherapy for neuropathic pain in adults: a systematic review and meta-analysis. Lancet Neurol. 14(2), 162-173 (2015).

66. Attal N, Cruccu G, Baron R et al.; European Federation of Neurological Societies. EFNS guidelines on the pharmacological treatment of neuropathic pain: 2010 revision. Eur. J. Neurol. 17(9), 1113-e88 (2010).

67. Dubinsky RM, Kabbani H, El-Chami Z, Boutwell C, Ali H; Quality Standards Subcommittee of the American Academy of Neurology. Practice parameter: treatment of postherpetic neuralgia: an evidence-based report of the Quality Standards Subcommittee of the American Academy of Neurology. Neurology 63(6), 959-65 (2004).

68. Baron R, Mayoral V, Leijon G, Binder A, Steigerwald I, Serpell M. 5\% lidocaine medicated plaster versus pregabalin in post-herpetic neuralgia and diabetic polyneuropathy: an open-label, non-inferiority two-stage RCT study. Curr. Med. Res. Opin. 25(7), 1663-1676 (2009).

69. Sabatowski R, Hans G, Tacken I, Kapanadze S, Buchheister B, Baron R. Safety and efficacy outcomes of long-term treatment up to 4 years with 5\% lidocaine medicated plaster in patients with post-herpetic neuralgia. Curr. Med. Res. Opin. 28(8), 1337-1346 (2012).

70. Martini A, Del Balzo G, Schweiger V et al. Efficacy of lidocaine $5 \%$ medicated plaster (VERSATIS ${ }^{\circledR}$ ) in patients with localized neuropathic pain poorly responsive to pharmacological therapy. Minerva Med. 109(5), 344-351 (2018).

71. Clère F, Delorme-Morin C, George B et al. 5\% lidocaine medicated plaster in elderly patients with postherpetic neuralgia: results of a compassionate use programme in France. Drugs Aging 28(9), 693-702 (2011).

72. Baron R, Allegri M, Correa-Illanes G et al. The 5\% lidocaine-medicated plaster: its inclusion in international treatment guidelines for treating localized neuropathic pain, and clinical evidence supporting its use. Pain Ther. 5(2), 149-169 (2016). 